\title{
The dual policy in the dual economy - the political economy of urban bias in dictatorial regimes
}

\author{
Abdulaziz B. Shifa*
}

May 15, 2011

\begin{abstract}
One of the most common policy obstacles in the global effort against poverty is what is termed as "urban bias" where rural residents, who constitute majority of the poor in the world, face systematic bias against their economic interests by their own governments. This paper develops a simple political economy model of urban bias in dictatorial regimes. Equilibrium outcomes relating policy outcomes with economic structure, political power, and other behavioral and structural variables are analyzed. The model shows that anti-agricultural biases can emerge in primarily agrarian societies even if there is no bias in political power between urban and rural citizens. Evidence from recent World Bank country level panel data on biases against/for agriculture provides support for the model's prediction.
\end{abstract}

Keywords: Urban bias; rural poverty; dictatorship.

JEL Classification: O02, O17, P48, R00, D72.

\section{Introduction}

One of the major policy features that characterized many poor states is a heavy bias against the rural population. This bias stands out as one of the most important policy obstacles to poverty reduction as vast majority of the poorest households depend on farming for their livelihood. According to the Rural Poverty Report 2011, "1.4 billion people continue to live in extreme poverty, struggling to survive on less than US $\$ 1.25$ a day. More than two thirds of them reside in rural areas of developing countries." The bias was first articulated by Lipton and he coined the term "urban bias" in 1977 with his influential book Why Poor People Stay Poor: Urban Bias in World Development [Lipton, 1977]. Lipton identified such systematic bias against rural residents as the single most important source of deprivation for majority of

\footnotetext{
*Economics Department, Stockholm University. Email: abdulaziz.shifa@ne.su.se. Webpage: http://people.su.se/ ashif/. I am very much grateful to Daron Acemoglu, Camilo Garcia, John Hassler, Per Krusell, Masayuki Kudamatsu, James Robinson, Bernie Zaaruka and Dilan Ölcer for their helpful comments.
} 
the poor across the world. Bates (1984) latter documented cases of systematic antipeasant policies in Sub-Saharan Africa. Bates (1984) particularly provided extensive accounts of various tax instruments such as government-owned marketing boards with monopsony power to buy export products from peasants at administratively set low prices. Governments then sell those products at the prevailing world prices and pocket the surplus. Bates (1984) also show how governments in Sub-Saharan Africa manipulated exchange rates against exportable farm products and used other domestic policies to suppress prices of agricultural products (particularly food) in the domestic market. More recently, Bezemer and Headey (2008) single out urban bias as "the largest institutional impediment to growth and poverty reduction in the worlds poorest countries." This paper attempts to provide both an empirical and theoretical contribution to better understand the underlying political economy mechanisms driving the bias.

A formal political economy model is developed to explain urban bias. Main feature of the model is the focus on dictatorial regimes. The focus on non-democratic polity is a novelty of this model since both the empirical analysis in this paper and previous case studies of urban bias typically show that urban bias is primarily a feature of non-democratic regimes. Particular attention is given to the political environment so as to capture the main regime features that characterize a typical dictatorial regime. One of those features of dictatorial regimes is the role of intraelite conflict in power transfer. In many dictatorial regimes, conflicts within the ruling elite are major sources of threat to political power. A usual source of such threats is coup d'etat. Citizens may also play a role in those conflicts. For example, citizens can support certain factions within the ruling circle. On the other hand, regime insiders may use popular sentiments against the current leader to come to power. It is not unusual for regime insiders to capitalize on citizens dissatisfaction to justify coup d'etat against a leader. The model combines these features where regime insiders and citizens may have role to influence policies and force leader's overthrow. Equilibrium outcomes relating policy outcomes with economic structure, political power, and other behavioral and structural variables are analyzed.

The model provides testable predictions regarding political incentives and economic structure as defined by the relative size of different sectors in the economy. To test the main prediction of the model that relates to the link between policy bias (toward/against agriculture) and sectoral composition in dictatorial regimes, I have made use of the recent country level panel data set compiled by a team of researchers (Anderson and Valenzuela, 2008) measuring assistances (or taxes) to agricultural products and political institutions variables. The data suggests that the empirical evidence is consistent with the model's prediction.

This paper attempts to narrow the gap in the large literature on urban bias and agricultural policies that began with observing what appears to be a general pattern that poor countries tax agriculture while rich countries subsidize. Among the early works to notice this pattern are Bale and Lutz (1981), Honma and Hayami (1986), and Krueger et al. (1988). A large part of the early literature thus tries to find out differences in economic structure between the two groups of countries (i.e. "developed" versus "developing") that can possibly affect agricultural policies. The problem with this approach is that countries that differ in their economic structure 
also tend to differ in political structure. Bates and Rogerson (1980), for example, apply such approach using a coalitional analysis to study how differences in sectoral composition in the economy affect policy outcomes. In doing so, however, they implicitly assume that the coalitions both in industrialized and agrarian countries are formed under a homogeneous political environment. In a similar vein, another strand of the literature focuses on the difference in the labor share of agriculture across developed and developing countries. The argument here follows the group action logic forwarded by Olson (1971), where large share of agricultural labor is argued to weaken farmers lobbying ability by worsening the free-riding problem (Olson, 1986). Impact of increase in population share again is assumed to affect agricultural policies negatively irrespective of the political regime. My approach in this paper diverts from this tradition by focusing specifically on a particular regime type, namely dictatorship.

The other limitation with the above literature is that it disregards heterogeneity among both developing and developed countries, particularly heterogeneity in political institutions. Among many others, case studies of India (Varshney, 1998), South Korea (Kruger, 1992) and Costarica (Colburn, 1993) have shown the significant variations among developing countries ${ }^{1}$. This has led to a plethora of both empirical and theoretical literature regarding the impact of political institutions and ideology on policy outcomes. The empirical studies focus on estimating the average impact of changes in democratization, forms of government, voting rules and ideology on agricultural policies. Much of this literature however ignores the potential interaction between economic structure and political institutions. For example, a change in economic structure may have different impact depending on the type of political institutions, and vice versa. Unlike previously held view about the negative effect of agriculture labor share on pro-agricultural policies, Bates and Block (2010) for example show that, for African countries, "the existence of party competition turns the lobbying disadvantage of the rural majority into political advantage". By identifying the mechanisms that link changes in economic structure with political incentives under dictatorial regimes, this paper thus attempts to provide further insight regarding the interaction between changes in economic structure and political institutions.

As pointed out by Olper and Raimondi (2010), much of the early empirical literature has weak link with comparative political economy models. Latter attempts following Henning et al. (2002) and Olper and Raimondi (2004) largely relied on some modification of the voting models (e.g. Grossman and Helpman, 1994). Using voting model under imperfect information, Majumdar et al. (2004) for example show how urban residents may get favorable policy outcomes due to the information advantage they have compared to their rural counterparts. The voting models provide useful insights with carefully formulated theoretical arguments. However, their application is limited to democratic regimes leaves us with a big gap in our attempt to understand dictatorial regimes that constitute a large part of the developing world. By focusing on dictatorial regimes, the model developed in this paper thus attempts to narrow this gap. Swinnen (2010) provides detail review of the related literature.

\footnotetext{
${ }^{1} \mathrm{~A}$ number of other cases are discussed in articles in Journal of Development Studies, 1993, 29(4). Special Issue: Beyond Urban Bias.
} 
Finally, this paper broadly relates to the growing class of political economy literature trying to understand policy making in autocratic regimes. Acemoglu et al. (2003) and Padro-I-Miquel (2007) show how self-interested leaders maximize their rent and impose exploitative policies by capitalizing on political fragmentation of citizens. Besley and Kudamatsu (2007) discuss why some autocracies perform better than others.

The next section begins with laying down set-up of the model. It will then be followed by analysis of the equilibrium policy outcomes. Section 4 will take a look at correlates of agricultural policies and economic structure under different regime types to examine if the model's major prediction is consistent with patters in observed policies. The final section presents concluding remarks.

\section{The model}

This section will present a dynamic political economy model to explain anti-agricultural policies and their relationship with agricultural dominance in the economy. I will first present basic set up of the model in the next section. Then analysis of the equilibrium outcomes will follow.

\subsection{Setup: players, strategies and timing}

Consider a dynamic game among various groups within the society. Specifically, assume that there are four groups of players: an incumbent leader (denoted by $L$ ), a regime insider (denoted by $I$ ), a continuum of urban citizens (denoted by $U$ ) and a continuum of rural citizens (denoted by $R$ ).

Political influence and power rivalry is carried out through non-democratic means. The leader's objective is to maximize his rent (taxes collected) from output produced by citizens. While doing so, however, he faces certain constraints depending on the relative political strength of each group within the society. The main constraint is the threat he faces from his insider. Depending on strength of the insider, urban citizens and rural citizens, assume that there are four possibilities regarding how the insider can overthrow the leader. In this game, I consider these possibilities as exogenously given states of the world, and denote by $q \in\left\{q_{a}, q_{u r}, q_{u}, q_{r}\right\}$. If the state is $q_{a}$, the insider can overthrow the leader by himself; if $q=q_{u r}$, the insider can overthrow the leader with the support of either $U$ or $R$; if $q=q_{r}$, the insider can overthrow the leader only with the support of $R$; if $q=q_{u}$, the insider can overthrow the leader only with the support of $U$.

If an incumbent leader is overthrown, there is uncertainty regarding each group's relative political power in the future. Such uncertainties are typically the case following political uprisings in weakly institutionalized states. The uncertainty is captured by random changes in the state variable $q$ whenever there is change of power (i.e. leader overthrow). In each period, a total quantity of $y_{u}$ and $y_{r}$ is produced by the urban and rural sector, respectively. Timing of the game and the strategies by each group are as follows: 
Step 1 At time $t=0$ (the initial period), nature randomly selects the leader and the insider from the citizens and determines type of the state $q_{t} \in\left\{q_{a}, q_{u}, q_{r}, q_{u r}\right\}$.

Step 2 All players observe state of the world $q_{t}$.

Step 3 The leader announces the tax rates on both sectors $\tau_{u, t}^{\prime}, \tau_{r, t}^{\prime} \in[0, \bar{\tau}]$ for some $\bar{\tau} \in[0,1)$ and share of the rent to be given to the insider $\delta_{t}^{\prime}\left(\tau_{u, t}^{\prime} y_{u}+\tau_{r, t}^{\prime} y_{r}\right)$, with $\delta_{t}^{\prime} \in[0,1] .^{2}$

Step 4 The insider proposes whether to overthrow the leader. If so, whether to do it alone, with the support of $U$ or with support of $R$. Denote the insider's strategy by $\psi_{t}=\left(\psi_{a, t}, \psi_{u, t}, \psi_{r, t}\right) \in \Psi \equiv\{\{0,1\} \times\{0,1\} \times\{0,1\}\} . \psi_{a}=1$ if the insider decided to overthrow by himself; otherwise, $\psi_{a}=0$. Similarly, $\psi_{u}=1\left(\psi_{r}=1\right)$ if the insider calls for support of the urban (rural) citizens; otherwise, $\psi_{u}=0\left(\psi_{r}=0\right)$.

Step 5 Citizens decide whether to offer support for the insider's call: $z_{u, t}, z_{r, t} \in\{0,1\}$. If $z_{s, t}=1$ for $s \in\{u, r\}$ (i.e. if citizens participate in an overthrow), it costs them $\gamma y_{s}$ for some $\gamma>0$. Following Acemoglu and Robinson (2006), I assume that participating in a revolution to overthrow an incumbent is a costly activity. ${ }^{3}$

Step 6 If leader is not overthrown, $q_{t+1}=q_{t}, \tau_{u, t}=\tau_{u, t}^{\prime}, \tau_{r, t}=\tau_{r, t}^{\prime}$ and $\delta_{t}=\delta_{t}^{\prime}$; and the game continues from Step 2 in period $t+1$.

Step 7 If leader is overthrown, $\tau_{u, t}=\tau_{r, t}=0$. The leader gets 0 in the future. ${ }^{4}$ $q_{t+1}$ takes either of the four values with probabilities $p_{a}, p_{u}, p_{r}$ and $p_{u r}$; in period $t+1$, the game continues from Step 2 with the insider as a leader and a randomly selected citizen as an insider. This assumption implies that an insider who kicks out a leader and takes power will face similar rivalry from his own insider. Leaders change, but the political system/regime remains the same.

Payoffs for player $j$, denoted by $V^{j}$, are discounted sum of instantaneous consumptions $C_{t}^{j}$ :

$$
V^{j}=\sum_{t=0}^{\infty} \beta^{t} C_{t}^{j}
$$

\footnotetext{
${ }^{2}$ The assumption that $\bar{\tau}<1$ is a reduced form for non-political constraints that the leader faces. One such constraint is what is called the "dead-weight loss" where the actual revenue for the leader from announcing a tax rate of $\tau$ will be $\tau-\alpha \frac{\tau^{2}}{2}$ for some $\alpha>0$, see Meltzer and Richard (1981). The other constraint is what Acemoglu (2005) calls "economic power" of citizens where citizens can hide their output and evade taxes albeit with certain costs (such as resorting to informal activities which may give them lower returns) if the taxes are too high.

${ }^{3}$ The sequence between Step 4 and 5 is not necessary for the conclusion on tax rates. The equilibrium tax rates will still be the same even if we interchange Step 5 and Step 4

${ }^{4}$ An interpretation could be that he loses everything, potentially gets purged.
} 
where

$$
C_{t}^{j}= \begin{cases}\left(1-\delta_{t}\right)\left(\tau_{u, t} y_{u}+\tau_{r, t} y_{r}\right), & \text { if } j \text { is a leader in period } t \\ \delta_{t}\left(\tau_{u, t} y_{u}+\tau_{r, t} y_{r}\right), & \text { if } j \text { is an insider in period } t \\ \left(1-\tau_{s, t}-z_{s, t} \gamma\right) y_{s}, s \in\{u, r\}, & \text { if } j \text { is an ordinary citizen }\end{cases}
$$

\subsection{Analysis}

The equilibrium concept used is in this analysis is pure strategy Markov Perfect Equilibrium (henceforth MPE). The appealing feature of MPE is its analytical simplicity. Within each period, players play sub-game perfect equilibrium. And along the equilibrium path, equilibrium strategies are functions of the state variable $q$. The following definition presents a precise equilibrium concept used in this analysis.

Definition 1. The MPE of this game is a set of the value functions $\left\{V_{i}(q): i \in\right.$ $\{U, R, I, L\}\}$; strategy by the leader $\left(\tau_{u}, \tau_{r}, \delta\right)(q)$; strategy by citizens $z_{u}(q)$ and $z_{r}(q)$; and strategy by the current insider $\psi(q)$ such that:

- Given $\left(z_{r}, z_{u}, \psi\right)(q),\left(\tau_{u}, \tau_{r}, \delta\right)(q)$ and $V_{L}(q)$ solve

$$
V_{L}(q)=\max _{\tau_{u}, \tau_{r} \in[0, \bar{\tau}] ; \delta \in[0,1]}\left\{C_{L}\left(\tau_{u}, \tau_{u}, \delta,\left(z_{u}, z_{r}, \psi\right)(q), q\right)+\beta \mathbb{E} V_{L}\left(q^{\prime}\right)\right\}
$$

- Given $\left(z_{r}, \tau_{u}, \tau_{r}, \delta, \psi\right)(q), z_{u}(q)$ and $V_{U}(q)$ solve

$$
V_{U}(q)=\max _{z_{u} \in\{0,1\}}\left\{C_{U}\left(z_{u},\left(z_{r}, \tau_{u}, \tau_{r}, \delta, \psi\right)(q), q\right)+\beta \mathbb{E} V_{U}\left(q^{\prime}\right)\right\}
$$

- Given $\left(z_{u}, \tau_{u}, \tau_{u}, \delta, \psi\right)(q), z_{r}(q)$ and $V_{R}(q)$ solve

$$
V_{R}(q)=\max _{z_{r} \in\{0,1\}}\left\{C_{R}\left(z_{r}, z_{u}\left(\tau_{u}, \tau_{r}, \delta, \psi\right)(q), q\right)+\beta \mathbb{E} V_{R}\left(q^{\prime}\right)\right\}
$$

- Given $\left(z_{u}, z_{r}, \tau_{u}, \tau_{r}, \delta\right)(q),(\psi)(q)$, and $V_{I}(q)$ solve

$$
V_{I}(q)=\max _{\psi \in \Psi}\left\{C_{I}\left(\psi,\left(z_{r}, z_{u},\left(\tau_{u}, \tau_{r}, \delta\right)(q), q\right)+\beta \mathbb{E} V_{I}\left(q^{\prime}\right)\right\}\right.
$$

In equilibrium, the leader maximizes his rent $\left(1-\delta_{t}\right)\left(\tau_{u, t} y_{u}+\tau_{r, t} y_{r}\right)$ while appeasing either one or more of the groups $U, L$ and $I$ to secure his survival. Depending on model parameters, we will see that there are five cases with unique equilibrium tax rates in each case. These cases pertain to alternative assumptions about model parameters.

\section{Case 1:}

The first case pertains to the following assumption

$$
\tau_{u 1} y_{u}+\tau_{r 1} y_{r} \geq \bar{\tau}\left(y_{u}+y_{r}\right)-\beta E_{1}
$$


where we define $\tau_{u 1}, \tau_{r 1}$ and $E_{1}$ as follows:

$$
\begin{array}{r}
\tau_{u 1} \equiv \max \left\{\bar{\tau}, \frac{1}{1-\beta\left(p_{u}+p_{u r}\right)}\left(\gamma-\gamma \beta+\beta \bar{\tau}-\beta\left(p_{u}+p_{u r}\right) \bar{\tau}\right)\right\} \\
\tau_{r 1} \equiv \max \left\{\bar{\tau}, \frac{1}{1-\beta\left(p_{r}+p_{u r}\right)}\left(\gamma-\gamma \beta+\beta \bar{\tau}-\beta\left(p_{r}+p_{u r}\right) \bar{\tau}\right)\right\} \\
E_{1} \equiv \frac{1}{1+p_{a} \beta}\left(p_{u}\left(\tau_{u 1} y_{u}+\bar{\tau} y_{r}\right)+p_{r}\left(\bar{\tau} y_{u}+\tau_{r 1} y_{r}\right)+p_{u r}\left(\tau_{u 1} y_{u}+\tau_{r 1} y_{r}\right)+p_{a} \bar{\tau}\left(y_{u}+y_{r}\right)\right)
\end{array}
$$

We then have the following proposition about the equilibrium outcome under assumption A1.

Proposition 1 (MPE1). Given assumption A1, the MPE strategies of this game are

- $\tau_{u}\left(q_{u}\right)=\tau_{u}\left(q_{u r}\right)=\tau_{u 1}, \tau_{u}\left(q_{r}\right)=\tau_{u}\left(q_{a}\right)=\bar{\tau}$

- $\tau_{r}\left(q_{r}\right)=\tau_{r}\left(q_{u r}\right)=\tau_{r 1}, \tau_{r}\left(q_{u}\right)=\tau_{r}\left(q_{a}\right)=\bar{\tau}$

- $\delta\left(q_{u}\right)=\delta\left(q_{r}\right)=\delta\left(q_{u r}\right)=0$

- $\delta\left(q_{a}\right)=\delta^{*}$ such that $\delta^{*} \bar{\tau}\left(y_{u}+y_{r}\right)=\beta E_{1}$

- $\psi_{u}(q), \psi_{r}(q), z_{u}(q), z_{u}(q)=0$

Proof. In order to prove MPE1 is indeed an equilibrium, we follow the usual procedure where we first conjecture that MPE1 is an MPE and then verify the claim. ${ }^{5}$

Given the conjecture, note that the expected payoff for the insider from taking power is $E_{1}$. If he can, the insider wants to overthrow the leader as long as the leader's offer to the insider is less than the discounted value of becoming a leader, which is $\beta E_{1}$.

Note also that, when $q=q_{u}$ or $q=q_{u r}$, urban citizens are indifferent between paying the current tax $\tau_{u}$ and participating in leader's overthrow (upon the insider's call to do so) if

$$
\begin{array}{r}
\frac{1-\tau_{u}}{1-\beta}=1-\gamma+\frac{\beta}{1-\beta}\left(p_{u}\left(1-\tau_{u}\left(q_{u}\right)\right)+p_{u r}\left(1-\tau_{u}\left(q_{u r}\right)\right)+\left(p_{r}+p_{o}\right)(1-\bar{\tau})\right) \\
\Longrightarrow 1-\tau_{u}=1+\beta \gamma-\gamma-\beta+\beta \Gamma_{u} \Longrightarrow \tau_{u}=\gamma+\beta\left(1-\gamma-\Gamma_{u}\right)
\end{array}
$$

where

$$
\Gamma_{u}=p_{u}\left(1-\tau_{u}\left(q_{u}\right)\right)+p_{u r}\left(1-\tau_{u}\left(q_{u r}\right)\right)+\left(p_{r}+p_{o}\right)(1-\bar{\tau})
$$

In equilibrium, $\tau_{u}=\tau_{u}(q)=\tau_{u}\left(q_{u r}\right)$, which implies $\tau_{u}=\tau_{u 1}$. Similarly, when $q=q_{r}$ or $q=q_{u r}$, rural citizens are indifferent between paying the current tax $\tau_{r}$ and protesting if

$$
\begin{array}{r}
\frac{1-\tau_{r}}{1-\beta}=1-\gamma+\frac{\beta}{1-\beta}\left(p_{r}\left(1-\tau_{r}\left(q_{r}\right)\right)+p_{u r}\left(1-\tau_{r}\left(q_{u r}\right)\right)+\left(p_{u}+p_{o}\right)(1-\bar{\tau})\right) \\
\Longrightarrow 1-\tau_{r}=1+\beta \gamma-\gamma-\beta+\beta \Gamma_{r} \Longrightarrow \tau_{r}=\gamma+\beta\left(1-\gamma-\Gamma_{r}\right)
\end{array}
$$

\footnotetext{
${ }^{5}$ See for example, Hassler et al. (2003).
} 
where

$$
\Gamma_{r}=p_{r}\left(1-\tau_{r}\left(q_{r}\right)\right)+p_{u r}\left(1-\tau_{r}\left(q_{u r}\right)\right)+\left(p_{u}+p_{o}\right)(1-\bar{\tau})
$$

In equilibrium $\tau_{r}=\tau_{r}(q)=\tau_{r}\left(q_{u r}\right)$, which implies $\tau_{r}=\tau_{r 1}$.

The leader doesn't obviously has the incentive to decrease taxes below what is required to keep the urban and rural residents just indifferent between protesting or not (i.e. $\tau_{u 1}$ and $\tau_{r 1}$ ). If the leader increases taxes beyond $\tau_{u 1}$ and $\tau_{r 1}$, he has to appease the insider as citizens will support the insider's call for leader change. However, by assumption A1, increasing taxes to $\bar{\tau}$ and sharing the rent with insider is not optimal for the leader. So the leader proposes $\tau_{u 1}$ and $\tau_{r 1}$ as his optimal strategy. And knowing that he will not get support of the citizens, the insider doesn't have the incentive to call for overthrow of the leader.

Under the above equilibrium (MPE1), instead of instituting the maximum exploitative tax rate (i.e $\bar{\tau}$ ) and buying-off the regime insider, the leader decides to appease citizens by offering them lower tax rates $\left(\tau_{u 1}, \tau_{r 1} \leq \bar{\tau}\right)$ whenever the insider needs popular support to overthrow the leader (i.e. when the state is either of $q_{u}, q_{r}$ and $\left.q_{u r}\right)$. This is a rational strategy for the leader because the leader can impose large enough taxes without instigating citizens for political uprising to overthrow him.

Both $\tau_{u 1}$ and $\tau_{r 1}$ are increasing in $\gamma^{6}{ }^{6}$ This is so because, as the cost of overthrowing the leader increases, citizens are less willing to overthrow the leader even if the leader imposes high taxes. $\tau_{u 1}$ and $\tau_{r 1}$ are also increasing in $\beta$. This outcome is driven by the uncertainty following leader changes. The group that has political power today may lose such power as the state can change in the aftermath of leader overthrow. The more forward-looking citizens are, the more they worry that future political power may slip out of their hand if they overthrow the current leader. Knowing this, the leader can impose higher and higher taxes as citizens get more and more forward-looking. $\tau_{u 1}$ is decreasing in $p_{u}$ and $p_{u r}$, and increasing in $p_{r}$ and $p_{a}$. The intuition behind this result is that, when $p_{u}$ and $p_{u r}$ increase, the probability that urban residents will remain powerful (i.e the next state will be either $p_{u}$ or $p_{u r}$ ) is more likely if the current leader is overthrown. ${ }^{7}$ And as they feel more confident that power will remain in their hand, they will thus be less willing to accept higher taxes. Knowing this, the leader imposes a lower tax rate. Similarly, $\tau_{r 1}$ is decreasing in $p_{r}$ and $p_{u r}$, and increasing in $p_{u}$ and $p_{a}$.

\section{Case 2:}

The second case pertains to the situation such that the following assumption is satisfied.

$$
\begin{aligned}
\tau_{u 2} y_{u}+\tau_{r 2} y_{r} & <\bar{\tau}\left(y_{u}+y_{r}\right)-\beta E_{2} \\
\tau_{u 2} y_{u}+\bar{\tau} y_{r}, \bar{\tau} y_{u}+\tau_{r 2} y_{r} & \geq \bar{\tau}\left(y_{u}+y_{r}\right)-\beta E_{2}
\end{aligned}
$$

\footnotetext{
${ }^{6}$ Taking the derivatives, $\frac{\partial \tau_{r 1}}{\partial p_{r}}=\frac{-\beta(\bar{\tau}-\gamma)(1-\beta)}{\left[1-\beta\left(p_{r}+p_{u r}\right)\right]^{2}} \leq 0, \frac{\partial \tau_{u 1}}{\partial p_{u}}=\frac{-\beta(\bar{\tau}-\gamma)(1-\beta)}{\left[1-\beta\left(p_{u}+p_{u r}\right)\right]^{2}} \leq 0, \frac{\partial \tau_{u 1}}{\partial \gamma}=$ $\frac{1-\beta}{\left[1-\beta\left(p_{u}+p_{u r}\right)\right]^{2}} \geq 0, \quad \frac{\partial \tau_{r 1}}{\partial \gamma}=\frac{1-\beta}{\left[1-\beta\left(p_{r}+p_{u r}\right)\right]^{2}} \geq 0, \frac{\partial \tau_{r 1}}{\partial \beta}=\frac{(\bar{\tau}-\gamma)\left(1-\left(p_{r}+p_{u r}\right)\right)}{\left[1-\beta\left(p_{r}+p_{u r}\right)\right]^{2}} \geq 0, \frac{\partial \tau_{u 1}}{\partial \beta}=$ $\frac{(\bar{\tau}-\gamma)\left(1-\left(p_{u}+p_{u r}\right)\right)}{\left[1-\beta\left(p_{u}+p_{u r}\right)\right]^{2}} \geq 0$

${ }^{7}$ Such fear of losing political power is the main mechanism in what Padro-I-Miquel (2007) calls "the politics of fear" where leaders capitalize on citizens fear in ethnically divided societies.
} 
where $\tau_{u 2}, \tau_{r 2}$ and $E_{2}$ are defined as follows:

$$
\begin{array}{r}
\tau_{u 2} \equiv \max \left\{\bar{\tau}, \frac{1}{1-\beta p_{u}}\left(\gamma-\gamma \beta+\beta \bar{\tau}-\beta p_{u} \bar{\tau}\right)\right\} \\
\tau_{r 2} \equiv \max \left\{\bar{\tau}, \frac{1}{1-\beta p_{r}}\left(\gamma-\gamma \beta+\beta \bar{\tau}-\beta p_{r} \bar{\tau}\right)\right\} \\
E_{2} \equiv \frac{1}{1+\left(p_{a}+p_{u r}\right) \beta}\left(\begin{array}{r}
p_{u}\left(\tau_{u 2} y_{u}+\bar{\tau} y_{r}\right)+p_{r}\left(\bar{\tau} y_{u}+\tau_{r 2} y_{r}\right)+ \\
\left(p_{a}+p_{u r}\right) \bar{\tau}\left(y_{u}+y_{r}\right)
\end{array}\right)
\end{array}
$$

We then have the following proposition.

Proposition 2 (MPE2). Given assumption A2, the MPE strategies of this game are

- $\tau_{u}\left(q_{u}\right)=\tau_{u 2}, \tau_{u}\left(q_{r}\right)=\tau_{u}\left(q_{u r}\right)=\tau_{u}\left(q_{a}\right)=\bar{\tau}$

- $\tau_{r}\left(q_{r}\right)=\tau_{r 2}, \tau_{r}\left(q_{u r}\right)=\tau_{r}\left(q_{u}\right)=\tau_{r}\left(q_{a}\right)=\bar{\tau}$

- $\delta\left(q_{u}\right)=\delta\left(q_{r}\right)=0$

- $\delta\left(q_{u r}\right)=\delta\left(q_{a}\right)=\delta^{*}$ such that $\delta^{*} \bar{\tau}\left(y_{u}+y_{r}\right)=\beta E_{1}$

- $\psi_{u}(q), \psi_{r}(q), z_{u}(q), z_{u}(q)=0$

Proof. As in the proof for MPE1, we first conjecture that MPE2 is an MPE and verify the conjecture. Given the conjecture, the expected payoff for insider from taking power is $E_{2}$. If he can, the insider thus wants to overthrow the leader as long as his offer from the leader is less than $\beta E_{2}$.

When $q=q_{u r}$, the maximum urban and rural taxes the leader can impose without protest by the citizens is $\tau_{u 2}$ and $\tau_{r 2}$, respectively. But, by the assumption A2, the leader is better off by increasing taxes to $\bar{\tau}$ and sharing it with the insider. When $q=q_{u}$ (or $q=q_{r}$ ), the max urban (or rural) tax that urban (rural) citizens are willing to accept without resorting to protest is $\tau_{u 2}$ (or $\tau_{r 2}$ ). And, given assumption A2, setting those taxes is better for the leader than imposing the maximum tax rate $\bar{\tau}$ and sharing it with the insider.

The major difference between MPE2 and MPE1 is that, unlike in MPE1, the leader resorts to appeasing the insider and imposes the maximum tax rate $\bar{\tau}$ when the state is $q_{u r}$. This is so because, under assumption A2, offering low taxes simultaneously to both groups is now less attractive compared to imposing the maximum tax rate $\bar{\tau}$ on both groups and dividing up the rent with the insider.

Some of the results that we find in MPE1 also hold under MPE2 and for same reasons: both $\tau_{r 2}$ and $\tau_{u 1}$ are increasing in $\beta, p_{a}$ and $\gamma ; \tau_{u 2}$ is decreasing in $p_{u}$ and increasing in $p_{r}$; and $\tau_{r 2}$ is increasing in $p_{r}$ and decreasing in $p_{u}$. However, unlike in MPE1, both $\tau_{u 2}$ and $\tau_{r 2}$ are now increasing in $p_{u r}$.

8

${ }^{8}$ Taking the derivatives, $\frac{\partial \tau_{r 2}}{\partial p_{r}}=\frac{-\beta(\bar{\tau}-\gamma)(1-\beta)}{\left(1-\beta p_{r}\right)^{2}}<0, \frac{\partial \tau_{u 2}}{\partial p_{u}}=\frac{-\beta(\bar{\tau}-\gamma)(1-\beta)}{\left(1-\beta p_{u}\right)^{2}}<0, \frac{\partial \tau_{u 2}}{\partial \gamma}=\frac{1-\beta}{\left(1-\beta p_{u}\right)^{2}}>$ $0, \frac{\partial \tau_{r 2}}{\partial \gamma}=\frac{1-\beta}{\left(1-\beta p_{r}\right)^{2}}>0, \frac{\partial \tau_{r 2}}{\partial \beta}=\frac{(\bar{\tau}-\gamma)\left(1-p_{r}\right)}{\left(1-\beta p_{r}\right)^{2}}>0$. 


\section{Case 3:}

Now we consider the $3^{\text {rd }}$ case where the following conditions are satisfied.

$$
\begin{gathered}
\bar{\tau} y_{u}+\tau_{r 3} y_{r}<\bar{\tau}\left(y_{u}+y_{r}\right)-\beta E_{3} \\
\tau_{u 2} y_{u}+\bar{\tau} y_{r} \geq \bar{\tau}\left(y_{u}+y_{r}\right)-\beta E_{3}
\end{gathered}
$$

where $\tau_{r 3}$ and $E_{3}$ are defined as follows:

$$
\begin{array}{r}
\tau_{r 3} \equiv \max \{\bar{\tau}, \gamma+\beta(\bar{\tau}-\gamma)\} \\
E_{3} \equiv \frac{p_{u}\left(\tau_{u 2} y_{u}+\bar{\tau} y_{r}\right)+\left(1-p_{u}\right) \bar{\tau}\left(y_{u}+y_{r}\right)}{1+\left(1-p_{u}\right) \beta}
\end{array}
$$

Then the following proposition is true.

Proposition 3 (MPE3). Given assumption A3, the MPE strategies of this game are

- $\tau_{u}\left(q_{u}\right)=\tau_{u 2}, \tau_{u}\left(q_{u r}\right)=\tau_{u}\left(q_{r}\right)=\tau_{u}\left(q_{a}\right)=\bar{\tau}$

- $\tau_{r}(q)=\bar{\tau}$

- $\delta\left(q_{u}\right)=0$

- $\delta\left(q_{u r}\right)=\delta\left(q_{a}\right)=\delta\left(q_{r}\right)=\delta^{*}$ such that $\delta^{*} \bar{\tau}\left(y_{u}+y_{r}\right)=\beta E_{3}$

- $\psi_{u}(q), \psi_{r}(q), z_{u}(q), z_{u}(q)=0$

Proof. Under MPE3, the expected payoff for insider from taking power is $E_{3}$. And if he can, the insider wants to overthrow the leader as long as his offer from the leader is less than $\beta E_{3}$. When $q=q_{u r}$, the maximum urban taxes the leader can impose without facing protest from urban citizens is $\tau_{u 2}$. However, by assumption A3, the leader is better off by increasing taxes to $\bar{\tau}$ and sharing it with the insider. When $q=q_{u}$, the maximum urban (rural) tax is $\tau_{u 2}(\bar{\tau})$. And setting those taxes is better for the leader than increasing the urban tax further and sharing it with insider. When $q=q_{r}$, the max rural tax the leader can impose without facing protest from rural residents is $\left.\tau_{r 3}\right)$. And increasing the rural tax further and sharing it with insider is better for the leader than setting those taxes and retaining all the rent for himself.

Under MPE3, there is a bias against the rural citizens in the sense that the leader doesn't find it attractive to offer lower tax rate to the rural citizens when the state is $q_{r}$ whereas he offers a lower tax rate to the urban citizens (i.e $\tau_{u 2} \leq \bar{\tau}$ ) when the state is $q_{u}$. 


\section{Case 4:}

A symmetric MPE holds if we consider what can be viewed as an opposite of assumption A3. Assume that

$$
\begin{aligned}
& \tau_{u 3} y_{u}+\bar{\tau} y_{r}<\bar{\tau}\left(y_{u}+y_{r}\right)-\beta E_{4} \\
& \bar{\tau} y_{u}+\tau_{r 2} y_{r} \geq \bar{\tau}\left(y_{u}+y_{r}\right)-\beta E_{4}
\end{aligned}
$$

where $\tau_{u 3}$ and $E_{4}$ are defined as follows:

$$
\begin{array}{r}
\tau_{u 3} \equiv \max \{\bar{\tau}, \gamma+\beta(\bar{\tau}-\gamma)\} \\
E_{4} \equiv \frac{p_{r}\left(\bar{\tau} y_{u}+\tau_{r 2} y_{r}\right)+\left(1-p_{r}\right) \bar{\tau}\left(y_{u}+y_{r}\right)}{1+\left(1-p_{r}\right) \beta}
\end{array}
$$

Then the following proposition is true.

Proposition 4 (MPE4). Given assumption A4, the MPE strategies of this game are

- $\tau_{u}(q)=\bar{\tau}$

- $\tau_{r}\left(q_{r}\right)=\tau_{r 2}, \tau_{r}\left(q_{u r}\right)=\tau_{r}\left(q_{r}\right)=\tau_{r}\left(q_{a}\right)=\bar{\tau}$

- $\delta\left(q_{r}\right)=0$

- $\delta\left(q_{u r}\right)=\delta\left(q_{a}\right)=\delta\left(q_{r}\right)=\delta^{*}$ such that $\delta^{*} \bar{\tau}\left(y_{u}+y_{r}\right)=\beta E_{3}$

- $\psi_{u}(q), \psi_{r}(q), z_{u}(q), z_{u}(q)=0$

Proof. Follow similar steps as in the proof for MPE3 while replacing $E_{3}, \tau_{u 2}$ and $p_{u}$ with $E_{4}, \tau_{r 2}$ and $p_{r}$.

Under MPE4, the bias is against the urban sector. The leader imposes a lower tax rate (i.e. $\tau_{r 2} \leq \bar{\tau}$ ) on the rural citizens when the state is $q_{r}$ while imposing the maximum tax rate $\bar{\tau}$ on the urban residents when the state is $q_{u}$.

\section{Case 5:}

Finally, assume that

$$
\tau_{u 3} y_{u}+\bar{\tau} y_{r}, \bar{\tau} y_{u}+\tau_{r 3} y_{r}<\beta E_{5}
$$

where $E_{5} \equiv \bar{\tau}\left(y_{u}+y_{r}\right) /(1+\beta)$. Then the following proposition is true.

Proposition 5 (MPE5). Given assumption A5, the MPE strategies of this game are

- $\tau_{u}(q)=\tau_{r}(q)=\bar{\tau}$

- $\delta(q)=\frac{\beta}{1+\beta}$

- $\psi_{u}(q), \psi_{r}(q), z_{u}(q), z_{u}(q)=0$ 
Under MPE5, irrespective of the state, the leader always prefers imposing the maximum tax rate on both urban and rural citizens and share it with the insider.

The five equilibria listed under propositions 1 to 5 exhaust all the possible MPEs. In order to confirm this, note that the leader needs to appease at least one of the groups $U, R$ or $I$. And depending on model parameters and state of the world, the leader appeases the group in such a way that he maximizes his rent while ensuring his survival. For example, when the state is $q_{u}$, the leader compares his payoff from appeasing the urban residents (by offering them a tax rate lower than $\bar{\tau}$ ) with that of buying in the insider while imposing the maximum tax rate. Under MPE1, MPE2 and MPE3, the leader opts for the first option while he chooses the second option under MPE4 and MPE5. When the state is $q_{r}$, the leader relies on the support of rural citizens under MPE1, MPE2 and MP4 while he chooses to buy off the insider and impose $\bar{\tau}$ on the rural citizens under MPE3 and MPE5. When the state is $q_{u r}$, the leader appeases both urban and rural residents under MPE1 while it resorts to buying the insider and imposing the maximum tax rates on both groups under the other four equilibria. In all of the cases, the leader appeases the insider and imposes $\bar{\tau}$ if the state is $q_{a}$.

\section{Urban bias, political power and dominance of agriculture}

In this section, we will take a closer look at the interaction between policy outcomes and economic structure as measured by relative size of the two sectors. As we have seen from equilibrium analysis in the previous section, policy outcomes depend on which of the five cases prevail and, for a given case, which state of the world we are in. For example, the probability distribution affects not only the likelihood of each state within a given case, but it also affects which of the five cases will be realized. Depending on the state we are in, the probability distribution also affects the equilibrium tax rates. In order to conceptualize urban bias in the framework of this model and derive testable prediction, we thus need to have a comprehensive measure accounting for all of these factors. Lets hence consider expected tax rates on both sectors, denoted by $\mathbb{E} \tau_{u}\left(q_{u}\right)$ and $\mathbb{E} \tau_{u}\left(q_{r}\right)$, as such a measure where

$$
\begin{aligned}
& \mathbb{E} \tau_{u}=p_{u} \tau_{u}\left(q_{u}\right)+p_{r} \tau_{u}\left(q_{r}\right)+p_{u r} \tau_{u}\left(q_{u r}\right)+p_{a} \tau_{u}\left(q_{a}\right) \\
& \mathbb{E} \tau_{r}=p_{u} \tau_{r}\left(q_{u}\right)+p_{r} \tau_{r}\left(q_{r}\right)+p_{u r} \tau_{r}\left(q_{u r}\right)+p_{a} \tau_{r}\left(q_{a}\right)
\end{aligned}
$$

$\mathbb{E} \tau_{u}$ and $\mathbb{E} \tau_{r}$ can be interpreted as the expected tax rates in a randomly picked country characterized by the model parameters. Since $\tau_{u}(q)$ and $\tau_{r}(q)$ are equilibrium tax rates, $\mathbb{E} \tau_{u}\left(q_{u}\right)$ and $\mathbb{E} \tau_{u}\left(q_{r}\right)$ take into account the impacts of changes in model parameters (such as political power distribution and relative size of each sector) on the likelihood of each state, which of the five cases we will be in, and the tax rates within each case.

Increase in $p_{u}$ decreases $\mathbb{E} \tau_{u}$ under either of the assumptions A1, A2 and A3. This is so for two reasons. Firstly, in each of the the three cases, $\tau_{u}\left(q_{u}\right)$ decreases as $p_{u}$ increases. And $\mathbb{E} \tau_{u}$ decreases since $\tau_{u}\left(q_{u}\right)$ enters additively in the expression for $\tau_{u}\left(q_{u}\right)$. Secondly, under assumptions A1, A2 and A3, $\tau_{u}\left(q_{u}\right) \leq \tau_{u}\left(q_{r}\right), \tau_{u}\left(q_{u r}\right), \tau_{u}\left(q_{a}\right)$. 
Increase in $p_{u}$ decreases $\mathbb{E} \tau_{u}$ since higher $p_{u}$ means larger weight for the smaller term in the expression for $\mathbb{E} \tau_{u}$ and lower weight for the larger terms. Under assumption $\mathrm{A} 1$, increases in $p_{u}$ and $p_{u r}$ have the same effect on $\mathbb{E} \tau_{u}$. Under assumptions $\mathrm{A} 4$ and A5, both $p_{u}$ and $p_{u r}$ have no effect on $\mathbb{E} \tau_{u}$.

Similarly, increases in $p_{r}$ under assumptions A1, A2 and A4 decrease $\mathbb{E} \tau_{r}$. Under assumption A1, increases in $p_{r}$ and $p_{u r}$ have the same effect on $\mathbb{E} \tau_{r}$. Under assumptions $\mathrm{A} 3$ and A5, both $p_{r}$ and $p_{u r}$ have no effect on $\mathbb{E} \tau_{r}$. The following proposition summarizes these effects.

Proposition 6. $\mathbb{E} \tau_{u}$ is decreasing in $p_{u}$ if either of assumptions A1, A2 and A3 hold. It is decreasing in $p_{u r}$ if $A 1$ holds. Similarly, $\mathbb{E} \tau_{r}$ is decreasing in $p_{r}$ if either of assumptions A1, A2 and A4 hold. It is decreasing in $p_{u r}$ if A1 holds.

Proof. See the appendix.

The increase in agriculture's relative size $y_{r} / y_{u}$ can have a positive effect on $\mathbb{E} \tau_{r}$. This happens because, as share of the rural sector increases, a shift from either of the three equilibria MPE1, MPE2 and MPE4 to MPE3 may occur. Such bias against agriculture can occur despite the relative political power of the rural citizens.

The main intuition behind this result is that, when the relative size of agriculture increases, appeasing the rural population may require giving up a large amount of rent. As the agriculture's relative size increases, the equilibrium may move to MPE3 which features bias against agriculture. This bias is despite the absence of difference in political power between the rural and the urban citizens (as measured by $p_{u}$ and $p_{r}$ ). Consider the relative expected tax rates $\mathbb{E} \tau_{r} / \mathbb{E} \tau_{u}$ as a measure of bias against agriculture. There is no bias if $\mathbb{E} \tau_{r} / \mathbb{E} \tau_{u}=1$, the bias is against agriculture if $\mathbb{E} \tau_{r} / \mathbb{E} \tau_{u}>1$, and the bias is against the urban sector if $\mathbb{E} \tau_{r} / \mathbb{E} \tau_{u}<1$. We thus have the following proposition.

Proposition 7. Assume $p_{u}=p_{r}=p^{*}>0$, i.e. there is no bias in political power. For large enough $y_{r} / y_{u}, \mathbb{E} \tau_{r} / \mathbb{E} \tau_{u} \geq 1$. And if $(1-\beta)(\bar{\tau}-\gamma)>\beta \bar{\tau} /\left[1+\left(1-p^{*}\right) \beta\right]$, then $\mathbb{E} \tau_{r} / \mathbb{E} \tau_{u}>1$ for large enough $y_{r} / y_{u}$. Conversely, for small enough $y_{r} / y_{u}$, $\mathbb{E} \tau_{r} / \mathbb{E} \tau_{u} \leq 1$. And if $(1-\beta)(\bar{\tau}-\gamma)>\beta \bar{\tau} /\left[1+\left(1-p^{*}\right) \beta\right]$, then $\mathbb{E} \tau_{r} / \mathbb{E} \tau_{u}<1$ for small enough $y_{r} / y_{u}$.

Proof. See the appendix.

\section{Empirical evidence}

This section takes a look at the statistical correlates regarding the association between the dominance of agriculture in the national economy and anti-agricultural policies given by Proposition 7. I will first discuss the main variables in the analysis and data source. We will then proceed to regression analysis.

\section{Rates of Assistance}

The two key variables in this analysis are the nominal rate of assistance (NRA) and relative rates of assistance (RRA) to agriculture. Estimates for NRA and RRA are 
done and compiled by a team of researchers under auspices of the World Bank. The data source is Anderson and Valenzuela (2008).

NRAs measure the subsidies (or taxations) that the agricultural sector receives (or pays) as a result of mainly government-imposed measures. Details of the measurement steps are described in Anderson et al. (2008). For each country in the sample, NRAs are estimated for a variety of agricultural commodities. Then a weighted average of NRAs for each commodity is taken to estimate overall NRA to the agricultural sector in the country. The nominal rate of assistance that a particular agricultural product $i$ receives, denoted by $N R A_{i}$ is defined as

$$
N R A_{i}=\frac{D_{i}}{R_{i}}-1
$$

where $D_{i}$ denotes the actual return that a producer of agricultural product $i$ receives while $R_{i}$ denotes the return that would have prevailed under a free market condition. Agricultural commodity $i$ is said to have subsidized (or taxed) if $N R A_{i}>0$ (or $N R A_{i}<0$ ). The subsidies/taxes take various forms such as tariffs on competing imported items, export subsidies/taxes, direct production subsidies/taxes to farmers, exchange rate manipulations to impose subsidy/tax on imports and exports, and subsidies/taxes to inputs for production. The overall NRA that the agricultural sector receives is the computed as a weighted average of NRAs offered to each commodity.

$$
N R A=\sum_{i} \alpha_{i} N R A_{i}
$$

where $\alpha_{i}$ is the ratio of the commodity $i$ 's value to value of the country's total agricultural produce. So $\alpha_{i}$ measures the relative economic importance of commodity $i$ in the country's agricultural sector. For each country included in the sample, annual time series of NRAs are estimated spanning from year 1955 to 2007. For some countries, the time series may not cover the entire period of 1955-2007. Included in the estimation are a total of 75 countries. According to Anderson and Valenzuela (2008), the countries together account for 92 percent of the world's population and agricultural GDP and 95 percent of total GDP. They also account for more than 85 percent of farm production and employment in each of Africa, Asia, Latin America and the transition economies of Europe and Central Asia. NRAs are estimated for more than 70 different products, with an average of 11 per country. In aggregate the coverage represents around 70 percent of the gross value of agricultural production in the focus countries, and just under two-thirds of global farm production.

RRA on the other hand measures net assistances offered to agriculture relative to other sectors. It is computed using the formula

$$
R R A=\frac{1+N R A}{1+N R A_{\text {nonagri }}}-1
$$

where $N R A_{\text {nonagri }}$ measures the nominal rate of assistance offered to non-agricultural sectors. 


\section{Other variables}

As a measure of the relative importance (or extent of dominance) of agriculture in the national economy, the ratio of value-added by the agricultural sector to the nation's total value-added is used. The correlation between share of agriculture's value-added in the national economy and the NRA will be used to study the statistical relationship between agricultural dominance and anti-agricultural policy. At early level of development, ideological justifications have apparently been presented to justify resource extraction from the agricultural sector in order to finance stateled industrialization. Share of value-added by the manufacturing sector in the national economy is thus used to measure the impact of early industrialization on NRAs. Other variables included in the statistical analysis are ratio of agricultural to non-agricultural population and income from mineral and energy extraction. The agricultural population ratio is included to account for potential political impact of population size. Mineral and energy abundances are included to control for the potential impact of mineral and energy resource abundance on the overall economic institutions and agricultural policy. The data source for these variables is World Development Indicators 2010.

A measure of political freedom is used to study biases against/for agriculture across political regimes. The political measure is a categorical variable that assigns three values for each country during each year. Depending on the extent of political freedom that citizens have in a country, the country can be ranked as free, partially free or not free. This variable is used to distinguish between democracies and nondemocracies. The data source is Freedom in the World 2010.

\section{Estimation Results}

Tables 1 to 4 present fixed-effect panel regression estimates to investigate the relationship between output share of agriculture in the national economy (defined as the ratio of value added by agriculture to the total value added in the economy) and rate of assistances. An advantage of the fixed-effect estimate is that it controls for time-invariant factors such as geography and historical legacies. As the mechanisms outlined in the model pertain to non-democratic regimes, separate regressions based on political status are reported. In tables 1 and 2 , the dependent variable is NRA while we have RRA as the dependent variable in tables 3 and 4 .

In Table 1, we have regression estimates for regimes that are relatively nondemocratic (labeled as Not Free or Partially Free in the Freedom House category). The first column (A) includes agriculture's share of value added as the only righthand-side variable. The estimated coefficient is negative. As the output share of agriculture in the economy increases, countries tend to tax the agricultural sector more, which is consistent with Proposition 7. A unit increase in the share of agriculture decreases the NRA by almost a proportionate amount (0.92).

Abundance of natural resources such as minerals and energy may influence tax policies toward agriculture (Bates and Block, 2010). Resource abundance may also influence institutional quality (Sachs and Warner, 1995). The variables Energy Rich and Mineral Rich are dummy indicators to show whether a country is major producer of energy and mineral resources, respectively. The mineral are bauxite, copper, iron, 
Table 1: Share of agriculture and NRA in non-democracies

\begin{tabular}{|c|c|c|c|c|c|}
\hline & (A) & (B) & $(\mathrm{C})$ & (D) & $(\mathrm{E})$ \\
\hline Agri. value added (ratio) & $\begin{array}{c}-0.92^{* * *} \\
(0.26)\end{array}$ & $\begin{array}{c}-0.93^{* * *} \\
(0.27)\end{array}$ & $\begin{array}{c}-0.70 * * \\
(0.31)\end{array}$ & $\begin{array}{c}-0.74^{* *} \\
(0.35)\end{array}$ & $\begin{array}{c}-0.95^{* * *} \\
(0.34)\end{array}$ \\
\hline Energy Rich & & $\begin{array}{l}-0.02 \\
(0.05)\end{array}$ & $\begin{array}{l}-0.05 \\
(0.05)\end{array}$ & $\begin{array}{l}-0.03 \\
(0.05)\end{array}$ & \\
\hline Mineral Rich & & $\begin{array}{l}-0.04 \\
(0.03)\end{array}$ & $\begin{array}{l}-0.01 \\
(0.03)\end{array}$ & $\begin{array}{l}-0.01 \\
(0.03)\end{array}$ & \\
\hline Ratio of agri. to non-agri. pop. & & & $\begin{array}{c}-0.08 * * * \\
(0.03)\end{array}$ & $\begin{array}{c}-0.08^{* * *} \\
(0.03)\end{array}$ & $\begin{array}{c}-0.04^{* *} \\
(0.02)\end{array}$ \\
\hline Manuf. value added (ratio) & & & & $\begin{array}{c}1.51 \\
(1.23)\end{array}$ & $\begin{array}{c}0.80 \\
(1.13)\end{array}$ \\
\hline Manuf. value added (ratio)-square & & & & $\begin{array}{c}-5.46^{* *} \\
(2.44)\end{array}$ & $\begin{array}{l}-4.09^{*} \\
(2.28)\end{array}$ \\
\hline Energy Extraction(\% of GDP) & & & & & $\begin{array}{l}-0.00 \\
(0.00)\end{array}$ \\
\hline Mineral Extraction (\% of GDP) & & & & & $\begin{array}{c}-0.01^{* * *} \\
(0.00)\end{array}$ \\
\hline Constant & $\begin{array}{c}0.15^{* *} \\
(0.07)\end{array}$ & $\begin{array}{c}0.18^{* *} \\
(0.09)\end{array}$ & $\begin{array}{c}0.24^{* *} \\
(0.11)\end{array}$ & $\begin{array}{c}0.17 \\
(0.19)\end{array}$ & $\begin{array}{c}0.21 \\
(0.17)\end{array}$ \\
\hline Observations & 953 & 953 & 789 & 789 & 721 \\
\hline Countries & 44 & 44 & 38 & 38 & 36 \\
\hline R-Square & 0.073 & 0.077 & 0.125 & 0.159 & 0.194 \\
\hline
\end{tabular}

Standard errors in parentheses

${ }^{*} p<0.10,{ }^{* *} p<0.05,{ }^{* * *} p<0.01$ 
lead, nickel, phosphate, tin, zinc, gold and silver. The variable Mineral Rich assumes value 1 if share of value of mineral extracted in the country's GDP is higher than the median share in the sample observations. Similar categorization for abundance of energy resources is done with the variable Energy Rich. The energy resources included are crude oil, natural gas and coal.

Column (B) shows that the coefficient on share of agriculture remains significantly negative. Column (C) controls for the ratio of population employed in the agriculture to the population employed in non-agricultural. The relative size of the agricultural population is argued to have a negative effect on assistance to agriculture by reducing the lobbying incentive of farmers (Olson, 1986; Anderson, 1995). The estimated coefficient on agriculture's relative population share has the expected sign. The coefficient on share of agriculture is still significantly negative.

Table 2: Share of agriculture and NRA

\begin{tabular}{|c|c|c|c|c|c|}
\hline & $(\mathrm{A})$ & $(\mathrm{B})$ & (C) & (D) & $(\mathrm{E})$ \\
\hline Agri. value added (ratio) & $\begin{array}{c}0.53 \\
(0.69)\end{array}$ & $\begin{array}{c}0.62 \\
(0.72)\end{array}$ & $\begin{array}{c}0.10 \\
(0.59)\end{array}$ & $\begin{array}{c}0.02 \\
(0.54)\end{array}$ & $\begin{array}{l}-0.29 \\
(0.63)\end{array}$ \\
\hline Energy Rich & & $\begin{array}{c}0.01 \\
(0.08)\end{array}$ & $\begin{array}{l}-0.01 \\
(0.08)\end{array}$ & $\begin{array}{c}0.01 \\
(0.07)\end{array}$ & \\
\hline Mineral Rich & & $\begin{array}{l}-0.05 \\
(0.08)\end{array}$ & $\begin{array}{l}-0.02 \\
(0.07)\end{array}$ & $\begin{array}{l}-0.04 \\
(0.06)\end{array}$ & \\
\hline Ratio of agri. to non-agri. pop. & & & $\begin{array}{c}-0.30^{* *} \\
(0.12)\end{array}$ & $\begin{array}{l}-0.27 \\
(0.20)\end{array}$ & $\begin{array}{l}-0.19 \\
(0.25)\end{array}$ \\
\hline Manuf. value added (ratio) & & & & $\begin{array}{c}13.02^{* *} \\
(5.05)\end{array}$ & $\begin{array}{c}13.35^{* *} \\
(5.08)\end{array}$ \\
\hline Manuf. value added (ratio)-square & & & & $\begin{array}{c}-30.32^{* * *} \\
(10.58)\end{array}$ & $\begin{array}{c}-30.85^{* * *} \\
(10.64)\end{array}$ \\
\hline Energy Extraction( $\%$ of GDP) & & & & & $\begin{array}{l}-0.02 \\
(0.03)\end{array}$ \\
\hline Mineral Extraction ( $\%$ of GDP) & & & & & $\begin{array}{c}-0.05^{* *} \\
(0.02)\end{array}$ \\
\hline Constant & $\begin{array}{c}0.44^{* * *} \\
(0.06)\end{array}$ & $\begin{array}{c}0.45^{* * *} \\
(0.08)\end{array}$ & $\begin{array}{c}0.55^{* * *} \\
(0.07)\end{array}$ & $\begin{array}{l}-0.78 \\
(0.58)\end{array}$ & $\begin{array}{l}-0.78 \\
(0.55)\end{array}$ \\
\hline Observations & 998 & 998 & 848 & 848 & 845 \\
\hline Countries & 50 & 50 & 45 & 45 & 44 \\
\hline R-Square & 0.002 & 0.004 & 0.008 & 0.074 & 0.086 \\
\hline
\end{tabular}

Standard errors in parentheses

${ }^{*} p<0.10,{ }^{* *} p<0.05,{ }^{* * *} p<0.01$

Low level of industrialization and governments ambition to develop their manufacturing sector through resource transfer from the agricultural sector often mentioned as a reason for anti-agricultural policies in many developing countries (see 
e.g. Schiff and Valds, 2002; Krueger, 1996). To control for such effect, column (D) includes the value added share of the manufacturing sector in the country's total value added. Due to the potential non-linearity of this effect, partly because of the non-linear share of manufacturing sector in the stage of economic transformation, the square term is also included. The estimated coefficients show that taxes on agriculture decrease, albeit at a decreasing rate, with increase in output share of the manufacturing sector. Column (E) includes a more direct measure of resource abundance - share of the value of energy and mineral extraction in the GDP. Both in column (D) and (E), the relationship between share of agriculture in the national value added remains to have a significant negative relationship with NRA.

Table 3: Share of agriculture and RRA in non-democracies

\begin{tabular}{|c|c|c|c|c|c|}
\hline & (A) & (B) & (C) & (D) & $(\mathrm{E})$ \\
\hline Agri. value added (ratio) & $\begin{array}{c}-1.61^{* * *} \\
(0.31)\end{array}$ & $\begin{array}{c}-1.61^{* * *} \\
(0.33)\end{array}$ & $\begin{array}{c}-1.00^{* * * *} \\
(0.34)\end{array}$ & $\begin{array}{c}-1.00^{* *} \\
(0.42)\end{array}$ & $\begin{array}{c}-1.20^{* * *} \\
(0.42)\end{array}$ \\
\hline Energy Rich & & $\begin{array}{l}-0.06 \\
(0.07)\end{array}$ & $\begin{array}{l}-0.07 \\
(0.06)\end{array}$ & $\begin{array}{l}-0.06 \\
(0.05)\end{array}$ & \\
\hline Mineral Rich & & $\begin{array}{l}-0.06 \\
(0.04)\end{array}$ & $\begin{array}{l}-0.04 \\
(0.03)\end{array}$ & $\begin{array}{c}-0.05^{*} \\
(0.03)\end{array}$ & \\
\hline Ratio of agri. to non-agri. pop. & & & $\begin{array}{c}-0.10 * * * \\
(0.02)\end{array}$ & $\begin{array}{c}-0.10^{* * *} \\
(0.02)\end{array}$ & $\begin{array}{c}-0.08^{* * *} \\
(0.02)\end{array}$ \\
\hline Manuf. value added (ratio) & & & & $\begin{array}{c}2.04 \\
(1.30)\end{array}$ & $\begin{array}{c}1.15 \\
(1.25)\end{array}$ \\
\hline Manuf. value added (ratio)-square & & & & $\begin{array}{c}-6.63^{* *} \\
(2.70)\end{array}$ & $\begin{array}{c}-5.07^{*} \\
(2.60)\end{array}$ \\
\hline Energy Extraction(\% of GDP) & & & & & $\begin{array}{c}-0.01^{*} \\
(0.00)\end{array}$ \\
\hline Mineral Extraction (\% of GDP) & & & & & $\begin{array}{c}-0.01^{* * *} \\
(0.00)\end{array}$ \\
\hline Constant & $\begin{array}{c}0.16^{* *} \\
(0.08) \\
\end{array}$ & $\begin{array}{c}0.23^{* *} \\
(0.10)\end{array}$ & $\begin{array}{c}0.27^{* *} \\
(0.11)\end{array}$ & $\begin{array}{c}0.15 \\
(0.21) \\
\end{array}$ & $\begin{array}{c}0.22 \\
(0.19) \\
\end{array}$ \\
\hline Observations & 798 & 798 & 780 & 780 & 713 \\
\hline Countries & 36 & 36 & 35 & 35 & 33 \\
\hline R-Square & 0.163 & 0.174 & 0.210 & 0.246 & 0.284 \\
\hline
\end{tabular}

Similar regression exercise is done for democratic countries (categorized as Free by the Freedom House). Table 2 presents estimation results for those countries. Columns (A) - (E) show the estimated coefficients with alternative control variables. In all cases, the partial correlation between NRA and agriculture's value added share 
is statistically insignificant. This finding suggests that the relationship between output share of agricultural and anti-agricultural policies is primarily a feature of non-democratic regimes.

Table 4: Share of agriculture and RRA in democracies

\begin{tabular}{|c|c|c|c|c|c|}
\hline & (A) & (B) & (C) & (D) & $(\mathrm{E})$ \\
\hline Agri. value added (ratio) & $\begin{array}{l}-0.14 \\
(0.80)\end{array}$ & $\begin{array}{c}0.06 \\
(0.87)\end{array}$ & $\begin{array}{l}-0.13 \\
(0.70)\end{array}$ & $\begin{array}{l}-0.18 \\
(0.51)\end{array}$ & $\begin{array}{l}-0.58 \\
(0.57)\end{array}$ \\
\hline Energy Rich & & $\begin{array}{c}0.00 \\
(0.09)\end{array}$ & $\begin{array}{l}-0.01 \\
(0.09)\end{array}$ & $\begin{array}{c}0.01 \\
(0.08)\end{array}$ & \\
\hline Mineral Rich & & $\begin{array}{c}-0.10^{* *} \\
(0.05)\end{array}$ & $\begin{array}{l}-0.07 \\
(0.04)\end{array}$ & $\begin{array}{c}-0.08^{*} \\
(0.05)\end{array}$ & \\
\hline Ratio of agri. to non-agri. pop. & & & $\begin{array}{c}-0.46^{* *} \\
(0.19)\end{array}$ & $\begin{array}{c}-0.42^{* *} \\
(0.19)\end{array}$ & $\begin{array}{l}-0.35 \\
(0.21)\end{array}$ \\
\hline Manuf. value added (ratio) & & & & $\begin{array}{c}9.66^{* * *} \\
(3.03)\end{array}$ & $\begin{array}{c}9.58^{* * *} \\
(2.83)\end{array}$ \\
\hline Manuf. value added (ratio)-square & & & & $\begin{array}{c}-23.48^{* * *} \\
(6.59)\end{array}$ & $\begin{array}{c}-23.27^{* * *} \\
(6.44)\end{array}$ \\
\hline Energy Extraction(\% of GDP) & & & & & $\begin{array}{l}-0.02 \\
(0.02)\end{array}$ \\
\hline Mineral Extraction (\% of GDP) & & & & & $\begin{array}{c}-0.04^{*} \\
(0.02)\end{array}$ \\
\hline Constant & $\begin{array}{c}0.45^{* * *} \\
(0.06)\end{array}$ & $\begin{array}{c}0.48^{* * *} \\
(0.09)\end{array}$ & $\begin{array}{c}0.57^{* * *} \\
(0.08)\end{array}$ & $\begin{array}{l}-0.38 \\
(0.33)\end{array}$ & $\begin{array}{l}-0.35 \\
(0.30)\end{array}$ \\
\hline Observations & 933 & 933 & 815 & 815 & 812 \\
\hline Countries & 47 & 47 & 45 & 45 & 44 \\
\hline R-Square & 0.000 & 0.009 & 0.038 & 0.091 & 0.095 \\
\hline
\end{tabular}

Standard errors in parentheses

${ }^{*} p<0.10,{ }^{* *} p<0.05,{ }^{* * *} p<0.01$

Finally, Table 3 and 4 report estimation results with RRA as the dependent variable. Compared to NRA, RRA can be considered as a closer proxy for $\mathbb{E} \tau_{r} / \mathbb{E} \tau_{u}$ in Proposition 7 since it measures the relative transfers to the agricultural sector. The results confirm the negative relationship between share of agricultural output and tax rates in non-democracies whereas there is no significant relationship in democracies.

\section{Conclusion}

This paper has attempted to provide both theoretical and empirical contributions to better understand what is considered to be one of the most important policy 
constraint to poverty reduction, namely governments bias against their rural citizens who constitute large share of the poor. A formal political economy model is developed to explain urban bias. Unlike previous models of anti-agricultural policies that largely relied on some extension of voting models, the focus in this model is on dictatorial regimes. Equilibrium outcomes relating policy outcomes with economic structure, political power, and other behavioral and structural variables are analyzed. By identifying the mechanisms that link changes in economic structure with political incentives under dictatorial regimes, this paper thus attempts to provide further insight regarding the interaction between changes in economic structure and political institutions. The empirical evidence shows that different regime types respond differently to changes in economic structure. The reaction by non-democratic regimes to changes in output share of agriculture is consistent with the model's prediction.

\section{References}

Acemoglu, Daron, "Politics and economics in weak and strong states," Journal of Monetary Economics, October 2005, 52 (7), 1199-1226.

- and James A. Robinson, Economic Origins of Dictatorship and Democracy number 9780521855266. In 'Cambridge Books.', Cambridge University Press, 2006.

_, _, and Thierry Verdier, "Kleptocracy and Divide-and-Rule: A Model of Personal Rule," NBER Working Papers 10136, National Bureau of Economic Research, Inc December 2003.

Anderson, Kym, "Lobbying Incentives and the Pattern of Protection in Rich and Poor Countries," Economic Development and Cultural Change, 1995, 43 (2), pp. 401-423.

- and Ernesto Valenzuela, Estimates of Distortions to Agricultural Incentives, 1955 to 200\%, Washington DC: World Bank, October 2008.

_ , Marianne Kurzweil, Will Martin, Damiano Sandri, and Ernesto Valenzuela, "Methodology for Measuring Distortions to Agricultural Incentives," Agricultural Distortions Working Paper 48326, World Bank January 2008.

Bale, Malcolm D. and Ernst Lutz, "Price Distortions in Agriculture and Their Effects: An International Comparison," American Journal of Agricultural Economics, 1981, 63 (1), pp. 8-22.

Bates, Robert H., Markets and states in tropical Africa : the political basis of agricultural policies, [new ed.] ed., Berkeley: Univ. of California Press, 1984.

_ and Steven Block, "Political Economy of Agricultural Trade Interventions in Africa," in Kym Anderson, ed., The Political Economy of Agricultural Price Distortions, Cambridge University Press, 2010. 
- and William P. Rogerson, "Agriculture in development: A coalitional analysis," Public Choice, 1980, 35, 513-527. 10.1007/BF00140083.

Besley, Timothy J. and Masayuki Kudamatsu, "Making Autocracy Work," CEPR Discussion Papers 6371, C.E.P.R. Discussion Papers June 2007.

Bezemer, Dirk and Derek Headey, "Agriculture, Development, and Urban Bias," World Development, 2008, 36 (8), 1342 - 1364.

Colburn, Forrest D, "Exceptions to urban bias in Latin America: Cuba and Costa Rica," Journal of Development Studies, 1993, 29 (4).

Freedom in the World

Freedom in the World, Freedom House, 2010.

Grossman, Gene M and Elhanan Helpman, "Protection for Sale," American Economic Review, September 1994, 84 (4), 833-50.

Hassler, John, Josandeacute; V. Rodrandiacute;guez Mora, Kjetil Storesletten, and Abrizio Zilibotti, "The Survival of the Welfare State," American Economic Review, March 2003, 93 (1), 87-112.

Henning, Christian H.C.A., Kim Carolin Krause, and Carsten Struve, "Institutional Foundation Of Agricultural Protection: The Case Of Eu-Accession And Agricultural Policy In Eastern European Countries," Technical Report 2002.

Honma, Masayoshi and Yujiro Hayami, "Structure of agricultural protection in industrial countries," Journal of International Economics, 1986, 20 (1-2), 115 -129 .

Krueger, Anne O., "Political Economy of Agricultural Policy," Public Choice, 1996, 87 (1/2), pp. 163-175.

_, Maurice Schiff, and Alberto Valds, "Agricultural Incentives in Developing Countries: Measuring the Effect of Sectoral and Economywide Policies," The World Bank Economic Review, 1988, 2 (3), pp. 255-271.

Kruger, Anne O., "volume 5: A synthesis of the political economy in developing countries," in Anne O. Kruger, ed., The political economy of agricultural pricing policy, Baltimore: John Hopkins University Press, 1992.

Lipton, Michael, Why poor people stay poor : a study of urban bias in world development, London: Temple Smith, $197 \%$.

Majumdar, Sumon, Anandi Mani, and Sharun W. Mukand, "Politics, information and the urban bias," Journal of Development Economics, October 2004, 75 (1), $137-165$.

Meltzer, Allan H and Scott F Richard, "A Rational Theory of the Size of Government," Journal of Political Economy, October 1981, 89 (5), 914-27. 
Olper, Alessandro and Valentina Raimondi, "Political Institutions and Milk Policy Outcomes in OECD Countries," in W. Verbeke G. Van Huylenbroeck and L. Lauwers, eds., Role of Institutions in Rural Policies and Agricultural Markets, Elsevier, 2004.

_ and _, "Constitutional Rules and Agricultural Policy Outcomes," in Kym Anderson, ed., The Political Economy of Agricultural Price Distortions, Cambridge University Press, 2010.

Olson, Mancur, The Logic of Collective Action: Public Goods and the Theory of Groups, Cambridge, MA: Harvard University Press, 1971.

- , "The Exploitation and Subsidization of Agriculture in Developing and Developed Countrie," in Allen Maunder and Ulf Renbor, eds., Agriculture in a Turbulent World Econom, Aldershot, Englan: Gower, 1986.

Padro-I-Miquel, Gerard, "The Control of Politicians in Divided Societies: The Politics of Fear," Review of Economic Studies, October 2007, 74 (4), 1259-1274. Rural Poverty Report

Rural Poverty Report, International Fund for Agricultural Development, 2011.

Sachs, Jeffrey D. and Andrew M. Warner, "Natural Resource Abundance and Economic Growth," NBER Working Papers 5398, National Bureau of Economic Research, Inc December 1995.

Schiff, Maurice and Alberto Valds, "Chapter 27 Agriculture and the macroeconomy, with emphasis on developing countries," in Bruce L. Gardner and Gordon C. Rausser, eds., Agriculture and its External Linkages, Vol. 2, Part 1 of Handbook of Agricultural Economics, Elsevier, 2002, pp. 1421 - 1454.

Swinnen, Johan F.M., "Political Economy of Agricultural Distortions: The Literature to Date," in Kym Anderson, ed., The Political Economy of Agricultural Price Distortions, Cambridge University Press, 2010.

Varshney, Ashutosh, Democracy, development and the countryside: urban-rural struggles in India, Cambridge University Press, 1998.

World Development Indicators

World Development Indicators, Washington DC: World Bank, September 2010 . 


\section{Appendix}

\section{A. Proof of Prposition 6}

We take the derivatives of $\mathbb{E} \tau_{u}$ with respect to the probabilities and see if they are negative or positive.

$$
\begin{aligned}
\mathbb{E} \tau_{u} & =p_{u} \tau_{u}\left(q_{u}\right)+p_{r} \tau_{u}\left(q_{r}\right)+p_{u r} \tau_{u}\left(q_{u r}\right)+p_{a} \tau_{u}\left(q_{a}\right) \\
\Longrightarrow \frac{d \mathbb{E} \tau_{u}}{d p_{u}}= & \tau_{u}\left(q_{u}\right)+p_{u} \frac{\partial \tau_{u}\left(q_{u}\right)}{\partial p_{u}}-\tau_{u}\left(q_{r}\right)+p_{r} \frac{\partial \tau_{u}\left(q_{r}\right)}{\partial p_{u}}- \\
& \tau_{u}\left(q_{u r}\right)+p_{u r} \frac{\partial \tau_{u}\left(q_{u r}\right)}{\partial p_{u r}}-\tau_{u}\left(q_{a}\right)+p_{a} \frac{\partial \tau_{u}\left(q_{a}\right)}{\partial p_{a}}
\end{aligned}
$$

Under assumption A1, $\tau_{u}\left(q_{u}\right)=\tau_{u}\left(q_{u r}\right)=\tau_{u 1}, \tau_{u}\left(q_{a}\right)=\tau_{u}\left(q_{r}\right)=\bar{\tau}$. Thus

$$
\frac{d \mathbb{E} \tau_{u}}{d p_{u}}=\tau_{u 1}+p_{u} \frac{\partial \tau_{u 1}}{\partial p_{u}}-\bar{\tau}+p_{r} \times 0-\tau_{u 1}+p_{u r} \frac{\partial \tau_{u}\left(q_{u r}\right)}{\partial p_{u r}}-\bar{\tau}+p_{a} \times 0
$$

Since $\partial \tau_{u 1} / \partial p_{u}=\partial \tau_{u 1} / \partial p_{u r} \leq 0$

$$
\frac{d \mathbb{E} \tau_{u}}{d p_{u}}=\left(p_{u}+p_{u r}\right) \frac{\partial \tau_{u 1}}{\partial p_{u}}-2 \bar{\tau} \leq 0 .
$$

And since $d \mathbb{E} \tau_{u} / d p_{u}=d \mathbb{E} \tau_{u} / d p_{u r}$ under assumption A1, $\mathbb{E} \tau_{u}$ is also decreasing in $p_{u r}$.

Under assumption A2, $\tau_{u}\left(q_{u}\right)=\tau_{u 2}$ and $\tau_{u}\left(q_{u r}\right)=\tau_{u}\left(q_{a}\right)=\tau_{u}\left(q_{r}\right)=\bar{\tau}$. Thus

$$
\frac{d \mathbb{E} \tau_{u}}{d p_{u}}=\tau_{u 2}+p_{u} \frac{\partial \tau_{u 2}}{\partial p_{u}}-\bar{\tau}+p_{r} \times 0-\bar{\tau}+p_{u r} \times 0-\bar{\tau}+p_{a} \times 0 .
$$

Since $\tau_{u 2} / \partial p_{u} \leq 0$

$$
\frac{d \mathbb{E} \tau_{u}}{d p_{u}}=\tau_{u 2}+p_{u} \frac{\partial \tau_{u 2}}{\partial p_{u}}-3 \bar{\tau} \leq 0 .
$$

$d \mathbb{E} \tau_{u} / d p_{u}$ is also decreasing under assumption A3 since it has the same value as in the case with assumption A2.

Similar steps can be followed to prove that $\mathbb{E} \tau_{r}$ is decreasing in $p_{r}$ if either of assumptions A1, A2 and A4 hold, and that it is decreasing in $p_{u r}$ if A1 holds.

\section{B. Proof of Prposition 7}

We prove this propostion that given the condition $(1-\beta)(\tau-\gamma)>\beta / \tau\left[1+\left(1-p_{u}\right) \beta\right]$ is satisfied, for large enough $y_{r} / y_{u}$, assumption A3 is satisfied. Let $\sigma=y_{r} / y_{u}$. Dividing both sides of the second inequality in A3 by $y_{u}$, we get

$$
\tau_{u 2}+\bar{\tau} \sigma \geq \bar{\tau}(1+\sigma)-\beta \frac{E_{3}}{y_{u}} \Longrightarrow 0 \geq \bar{\tau}-\tau_{u 2}-\beta \frac{E_{3}}{y_{u}}
$$

Then take derivative the RHS of (7) with respect to $\sigma$

$$
\frac{\partial}{\partial \sigma}\left(\bar{\tau}-\tau_{u 2}+-\beta \frac{E_{3}}{y_{u}}\right)=-\beta \frac{\partial}{\partial \sigma}\left(\frac{E_{3}}{y_{u}}\right)=-\beta \frac{\bar{\tau}}{1+\left(1-p_{u}\right) \beta}
$$


The derivative given by (8) is a negative constant. Hence, the RHS of (7) is a linear function of $\sigma$. And since the slope is negative, for large enough $\sigma$, the inequality (7) is satisfied (hence second inequality of assumption A3 is satisfied).

Now lets derive similar condition for the first inequality in assumption A3. Divide both sides of the inequality by $y_{u}$ to get

$$
\bar{\tau}+\tau_{r 3} \sigma<\bar{\tau}(1+\sigma)-\beta \frac{E_{3}}{y_{u}} \Longrightarrow 0<\bar{\tau} \sigma-\tau_{r 3} \sigma-\beta \frac{E_{3}}{y_{u}}
$$

Taking derivative of the RHS of (9) with respect to $\sigma$,

$$
\frac{\partial}{\partial \sigma}\left(\bar{\tau} \sigma-\tau_{r 3} \sigma-\beta \frac{E_{3}}{y_{u}}\right)=\bar{\tau}-\tau_{r 3}-\beta \frac{\partial}{\partial \sigma}\left(\frac{E_{3}}{y_{u}}\right)=\bar{\tau}-\tau_{r 3}-\beta \frac{\bar{\tau}}{1+\left(1-p_{u}\right) \beta}
$$

Using the value for $\tau_{r 3}$ from equation (1), equation (10) becomes

$$
\frac{\partial}{\partial \sigma}\left(\bar{\tau} \sigma-\tau_{r 3} \sigma-\beta \frac{E_{3}}{y_{u}}\right)=(1-\beta)(\bar{\tau}-\gamma)-\frac{\beta \bar{\tau}}{1+\left(1-p_{u}\right) \beta}
$$

Again the RHS of inequality (9) is a linear function of $\sigma$. And if $(1-\beta)(\tau-$ $\gamma)>\beta \tau /\left[1+\left(1-p_{u}\right) \beta\right]$, the coefficient on $\sigma$ is negative. Hence, for large enough $\sigma$, inequality (9) is satisfied (hence the first inequality in assumption A3 is also satisfied).

Similar steps can be followed to prove that for small enough $y_{r} / y_{u}, \mathbb{E} \tau_{r} / \mathbb{E} \tau_{u} \leq 1$. 